\title{
Author Correction: AHR is a Zika virus host factor and a candidate target for antiviral therapy
}

Federico Giovannoni, Irene Bosch, Carolina Manganeli Polonio, María F. Torti, Michael A. Wheeler, Zhaorong Li (iD, Leonardo Romorini, María S. Rodriguez Varela, Veit Rothhammer, Andreia Barroso DD, Emily C. Tjon, Liliana M. Sanmarco, Maisa C. Takenaka, Seyed Mohamad Sadegh Modaresi, Cristina Gutiérrez-Vázquez, Nágela Ghabdan Zanluqui, Nilton Barreto dos Santos, Carolina Demarchi Munhoz D , Zhongyan Wang, Elsa B. Damonte, David Sherr, Lee Gehrke, Jean Pierre Schatzmann Peron (D), Cybele C. Garcia (D) and Francisco J. Quintana (D)

Correction to: Nature Neuroscience https://doi.org/10.1038/s41593-020-0664-0, published online 20 July 2020.

In the version of this article initially published online, the last sentence of the Author Contributions should read, "J.P.S.P., C.C.G. and F.J.Q. designed and supervised the study and edited the manuscript." The error has been corrected in the print, PDF and HTML versions of this article.

Published online: 10 August 2020

https://doi.org/10.1038/s41593-020-0700-0

(c) The Author(s), under exclusive licence to Springer Nature America, Inc. 2020

\section{Author Correction: Striatal neurons directly converted from Huntington's disease patient fibroblasts recapitulate age-associated disease phenotypes}

Matheus B. Victor (D), Michelle Richner, Hannah E. Olsen, Seong Won Lee, Alejandro M. Monteys, Chunyu Ma, Christine J. Huh, Bo Zhang, Beverly L. Davidson, X. William Yang and Andrew S. Yoo (D)

Correction to: Nature Neuroscience https://doi.org/10.1038/s41593-018-0075-7, published online 5 February 2018.

In the version of this article initially published, two plasmids were listed incorrectly in the Methods section. Plasmid phDLX1-N174 (\#66859) should be \#60859, and phDLX2-N174 (\#66860) should be 60860. The error has been corrected in the PDF and HTML versions of this article.

Published online: 2 September 2020

https://doi.org/10.1038/s41593-020-00714-3

(c) The Author(s), under exclusive licence to Springer Nature America, Inc. 2020 